\title{
Living with a pacemaker: patient-reported outcome of a pacemaker system
}

Peter Magnusson ${ }^{1,2^{*}}$ (D) and Per Liv ${ }^{2}$

\begin{abstract}
Background: The aim of this study was to assess among pacemaker patients their overall satisfaction with the pacemaker system, pain, soreness/discomfort, cosmetic results, restrictions due to impaired movement of the shoulder/arm/chest, related sleep disturbances, and concern about possible device malfunction.
\end{abstract}

Methods: The seven-item questionnaire was mailed to patients from a single center who had a pacemaker implant or replacement between 2006 and 2016. A higher score indicated worse outcome on a visual analog scale (VAS) of 0-100 mm.

Results: The response rate was $75.5 \%$ and 342 questionniares were analyzed. Median age of respondents was 77. 6 years and $57.0 \%$ were males. In total, 65 complications requiring surgery (10 pocket corrections (2.9\%), 5 in females) occurred during a median follow-up of 5.6 years. The distribution of the primary outcome had a median score of 5 while the 75th percentile was 13 . Cosmetic appearance was significantly associated with reoperation (but not other variables). Overall scores for men and women were 5 vs. 6 , respectively, which achieved significance $(p=0.042)$. Median ratings of pain, soreness/discomfort, cosmetic appearance, range of motion, sleep, and concern about device malfunction were all $\leq 5$. Females reported worse outcomes for all questions, except for cosmetic results and concern about malfunction.

Conclusions: The vast majority of patients report excellent overall satisfaction with the pacemaker system, and are not affected by pain, soreness/discomfort, or concern about device malfunction. They also reported favourable outcomes with respect to cosmetic results, shoulder movement, and sleep. However, some patients underwent a surgical correction of the pacemaker pocket.

Keywords: Arrhythmia, Complication, Experience, Pacemaker, Pocket

\section{Background}

A permanent pacemaker is indicated in patients with bradycardia, i.e. second- or third-degree atrioventricular block, significant sinus node dysfunction, tachycardia-bradycardia syndrome, bundle branch block with a history of syncope, and, in specific circumstances, in various disease states, according to guidelines [1]. In symptomatic patients with heart failure, with an ejection fraction $\leq 40 \%$ and bundle branch block despite optimal medical therapy, cardiac resynchronization therapy (CRT) is indicated [1]. The implantation incidence in Western Europe is 938 bradycardia pacemakers and 140 CRT devices per million annually [2].

\footnotetext{
* Correspondence: peter.magnusson@regiongavleborg.se

${ }^{1}$ Cardiology Research Unit, Department of Medicine, Karolinska Institutet, Karolinska University Hospital/Solna, SE-171 76 Stockholm, Sweden

${ }^{2}$ Centre for Research and Development, Uppsala University/Region Gävleborg, Gävle, Sweden
}

(c) The Author(s). 2018 Open Access This article is distributed under the terms of the Creative Commons Attribution 4.0 International License (http://creativecommons.org/licenses/by/4.0/), which permits unrestricted use, distribution, and reproduction in any medium, provided you give appropriate credit to the original author(s) and the source, provide a link to the Creative Commons license, and indicate if changes were made. The Creative Commons Public Domain Dedication waiver (http://creativecommons.org/publicdomain/zero/1.0/) applies to the data made available in this article, unless otherwise stated. or AAI) or two leads (DDD) fixated in the right side of the heart; a CRT devices adds a special lead on the left side. The lead(s) is plugged into a pacemaker device $(50 \times 50 \mathrm{~mm}$ and $5-7 \mathrm{~mm}$ thick and weight $20-30 \mathrm{~g})$, which is inserted beneath the collarbone, typically on the left side. Perioperative complications can occur during vascular access (pneumothorax, arterial puncture, and nerve plexus injury) and during lead fixation in the myocardial wall (perforation, tricuspid valve damage, and sustained arrhythmias) [3, 4]. Postoperative and long-term complications requiring surgical revision include infections, lead malfunction due to oversensing or mechanical failure, technical device failure, and discomfort with the device system [5]. In many countries, these complications are reported in a national register e.g. the 
Swedish Pacemaker Registry and the Danish Pacemaker Register $[6,7]$. In a validation study of the latter registry, 9.5\% of cardiac implantable device patients were affected by complications after half a year [8]. However, the patient-reported experience, specifically with regard to the pacemaker system, is not completely understood [9]. Furhermore, generic questionnaires on health-related quality of life lack disease specificity [10]. Therefore we developed a questionnaire to assess overall satisfaction with the pacemaker system (primary outcome), and to assess secondary outcomes of pain, soreness/discomfort, cosmetic results, restrictions of movement impairment of the shoulder/arm/chest, sleep disturbances related to the pacemaker generator, and concern about device malfunction. We aimed to address these research questions in a cross-sectional cohort study in an unselected population of pacemaker patients with various duration since first implantation.

\section{Methods \\ Setting}

The records of all patients $\geq 18$ years who recieved an initial pacemaker or a replacement pacemaker at Gävle Hospital, Region Gävleborg between December 2006 and December 2016 were extracted from the electronical system Provisio $^{\mathrm{TM}}$.

We excluded patients with a history of primary a CRT implant and/or an implantable defibrillator. We used search codes FPE00, FPE10, FPE20, and FPE40 according to the International Code of Disease and Classification [11], which have not changed during the study period.

\section{Data collection and power analysis}

The search yielded 2950 patients. A power analysis was performed using Monte-Carlo simulations from a hypothetical outcome of the primary outcome: log-normal distribution, truncated at $10 \mathrm{~mm}$ with a log-scale mean score of 1.6 and a log-scale standard deviation of 1 . The simulations showed that 400 patients would under the described circumstances be sufficient to estimate the median VAS score of with an expected 95\% confidence interval width of $7 \mathrm{~mm}$, as estimated from $\mathrm{BCa}$ non-parametric bootstrapping. This was deemed to be a sufficient precision.

To compensate for non-responses, one fifth of the patients (590 out of 2950) were randomly selected using a computer script written in $R$ and manually entered into the daily updated census register to ensure that we included only living patients [12]. After removal of duplicates, the final sample consisted of 453 patients, who were mailed the questionnaire.

In early January of 2017, the questionnaire was sent by regular mail together with information about the study, an informed consent form, and a return envelope. A reminder was sent 6 weeks later and a final reminder another 6 8 weeks thereafter. A phone call preceded the last reminder. In addition, a phone call was made to patients who returned incomplete questionnaires.

\section{The questionnaire}

The questionnaire consisted of seven questions, to be answered on a $100 \mathrm{~mm}$ visual analog scale (VAS) with wording and pictures at each end (see example Fig. 1). A higher score indicates worse outcome.

The questions appear below with the words at either extreme on the VAS shown in parentheses.

1. How satisfied are you overall with your pacemaker? (Very satisfied, Very dissatisfied).

2. How much pain related to your pacemaker do you experience? (No pain, Considerable pain).

3. How much are you bothered by sorenesss/ discomfort from the pacemaker? (No soreness/ discomfort, Considerable soreness/discomfort).

4. How do you feel about the cosmetic appearance of your pacemaker? (Very Good, Very bad).

5. Do you experience any restrictions of movement of shoulder/arm/chest related to your pacemaker? (No restriction of movement, Considerable restriction of movement).

6. How would you rate any sleep disturbances related to your pacemaker generator? (No sleep disturbance, Considerable sleep disturbance).

7. How much concern do you feel that your pacemaker will stop working or malfunction? (No concern, Always concerned).

The questionnaire was developed by the authors and face validity was addressed by input from physicians and nurses involved in the follow-up of pacemaker patients. Laypeople were consulted to assure that the form was clearly understood and easy to follow. As generic quality-of-life instruments could not capture the specific patient-reported outcomes this paper aimed to address and as no suitable disease-specific instrument could be found in the literature, we developed a new questionnaire based on clinical experience. This new questionnaire has not been evaluated with regards to reliability or validity, which we recognize as a limitation.

1. How satisfied are you overall with your pacemaker?

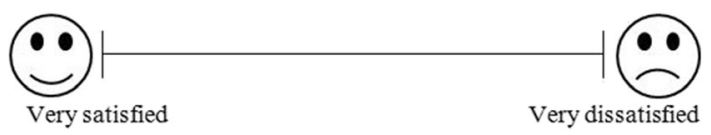

Fig. 1 Question 1 in the questionnaire. A higher score indicates worse outcome 


\section{Other variables}

In addition to the questionnaire, we asked patients to fill in their current medications, which were categorized as follows: sleeping pills (zolpidem, propiomazin) including other benzodiazepines, acetaminophen (paracetamol), selective serotonin reuptake inhibitors, opioids, and corticosteroids. Complications were defined as those requiring surgery involving the pacemaker system, i.e. opening of the pacemaker pocket. Information on complications was obtained from medical records and registry data.

\section{Statistics}

Numeric data were described as frequencies, percentages, medians (interquartile range [IQR]), means (standard deviation [SD]), and percentiles. All VAS-scores on the questionnaire were reported in millimeters $(\mathrm{mm})$. Tests of differences in VAS results between subgroups were performed using the Mann-Whitney U-test. Associations between continuous variables were assessed using Spearman's correlation coefficient. Possible differences in proportion of response rates between males and females were tested using Fisher's exact test. The choice of using non-parametric statistics was made based on non-normality of all measured variables, as seen from graphically examination of data. All statistical tests were two-sided with a significance level of 0.05. The database in Excel 2010 (Microsoft Corporation, Redmond, WA) was imported for analyses using $R$ (R Core Team, 2015).

\section{Ethics}

The Regional Ethical Committee in Uppsala approved the study (protocol number 2016/478).

\section{Results}

A total of 342 questionniares were analyzed. Ages ranged from 30 to 100 years, with a median age of 77.6 years (interquartile range [IQR]: 70-84) and the mean age was 75.9 years (standard deviation [SD] 12.0). There were more males $(n=195 ; 57.0 \%)$ than females $(n$ $=147 ; 43 \%)$. Patients had DDD (76.6\%), single-chamber (17.0\%), or CRT (6.4\%) pacemakers. During the median time since primary pacemaker implant of 5.6 years (mean 6.5 years, SD 5.1), 65 complications requiring surgical intervention occurred, mainly lead-related malfunction or perforation. One patient had two complications. Notably, 10 patients (2.9\%), of whom 5 were females, underwent pacemaker pocket revision, i.e. a correction. Median time since last device surgery was 4.3 years (IQR 1.73-8.1 years). In our study, over a median time since primary implant of 5.6 years, patients underwent device replacement either before battery depletion $(n=104$, $30.4 \%)$ or due to complications $(n=51,14.9 \%)$. The pharmacological regimens that could influence the patient's pacemaker experience were mainly sleeping pills including benzodiazepines $(n=28 ; 7.3 \%)$, acetaminophen (paracetamol) $(n=18 ; 5.3 \%)$, selective serotonin reuptake inhibitors $(\mathrm{n}=18 ; 5.3 \%)$, opioids $(n=8 ; 2.3 \%)$, and corticosteroids $(n=4 ; 1.2 \%)$. More than half of the patients $(59.4 \%)$ were overweight (body mass index [BMI] > 25) at the time they completed the questionnaire. Median BMI was $26.0 \mathrm{~kg} / \mathrm{m}^{2}$ (IQR 24.6-29.3) and only $3.3 \%$ reported $\mathrm{BMI}<20 \mathrm{~kg} / \mathrm{m}^{2}$. Patient characteristics are summarized in Table 1.

\section{Analysis of non-response}

The response rate of the questionnaire was $75.5 \%$. Reasons for non-response were as follows: dementia $(n=10)$, no registered postal address/emigration $(n=6)$, or unknown $(n=95)$. Fisher's exact test revealed no stastically significant difference in response rate with regard to sex; $78.0 \%$ among males returned the questionnaire and females $72.4 \%(p=0.188)$. Non-responders were significantly older than responders (median age: 82.4 years vs 77.6 years, $p=0.018$ ).

Table 1 Characteristics of 342 pacemaker patients

\begin{tabular}{ll}
\hline Variable & $\mathrm{n}$ \\
\hline Number of patients & 342 \\
Median age (years) & $77.6($ IQR $70.4-84.2)$ \\
Males & $195(57.0 \%)$ \\
Pacemaker type & \\
DDD & $262(76.6 \%)$ \\
WI & $51(14.9 \%)$ \\
AAl & $7(2 \%)$ \\
CRT-P & $22(6.4 \%)$ \\
Number of procedures & \\
1 & $229(67.0 \%)$ \\
2 & $67(19.6 \%)$ \\
3 & $29(8.5 \%)$ \\
4 & $15(4.4 \%)$ \\
5 & $1(0.3 \%)$ \\
6 & $1(0.3 \%)$ \\
Complications requiring reintervention & \\
Lead malfunction & \\
Pocket correction & $40(11.7 \%)$ \\
Perforation & $10(2.9 \%)$ \\
Extraction & $5(1.5 \%)$ \\
Exploration unipolar lead & $9(2.6 \%)$ \\
Body-mass index (kg/m $\left.{ }^{2}\right)$ & $1(0.3 \%)$ \\
\hline $20-25$ & $11(3.3 \%)$ \\
& $119(35.7 \%)$ \\
\hline 0 & $130(39 \%)$ \\
\hline & $73(21.9 \%)$ \\
\hline &
\end{tabular}




\section{Primary outcome}

As for the ratings of each seven questions, the distribution of the primary outcome overall satisfaction was heavily skewed to the right (Fig. 2). Median score was 5 while the 75th percentile was 13 and the 95th percentile 44.9 .

Men and women had similar median scores (5 vs. 6, respectively) but the Mann-Whitney $U$ test revealed statistical significance $(p=0.042)$ driven by differences in the higher percentiles (75th percentile:15.5 vs 11.5; 95th percentile: 54.2 vs 30.3 ). Patients who underwent reoperation did not report a significantly different outcome in overall satisfaction compared to those who did not undergo a revision $(p=0.14)$.

\section{Secondary outcomes}

Median ratings of pain, soreness/discomfort, cosmetic results, movement, sleep, and concern about device malfunction were all $\leq 5$. The 75 th percentiles ranged from 8 (pain) to 16 (cosmetic results) and the 95th percentile ranged from 38 (pain) to 54 (movement), see Tables 2 and 3. Statistically significant differences between males and females were found for all questions, except for cosmetic results and concern about device malfunction. Reoperation was significantly associated withworse outcome for cosmetic results, but not for the other variables.

\section{Correlations}

None of the seven outcome scores correlated significantly to patient age at the time of evaluation (Spearman's rho ranging between 0.00 and 0.16 , all $p$-values $\geq 0.355$ ), time since the first implantation (Spearman's rho between - 0.09 and -0.01 , all $p>0.12$ ) or $B M I$ (Spearman's rho between - 0.10 and 0.00, all $p>0.48$ ). However, a longer time since last pacemaker surgery was significantly correlated to better outcomes for all questions (overall satisfaction rho $=-0.26, p<0.001$; pain
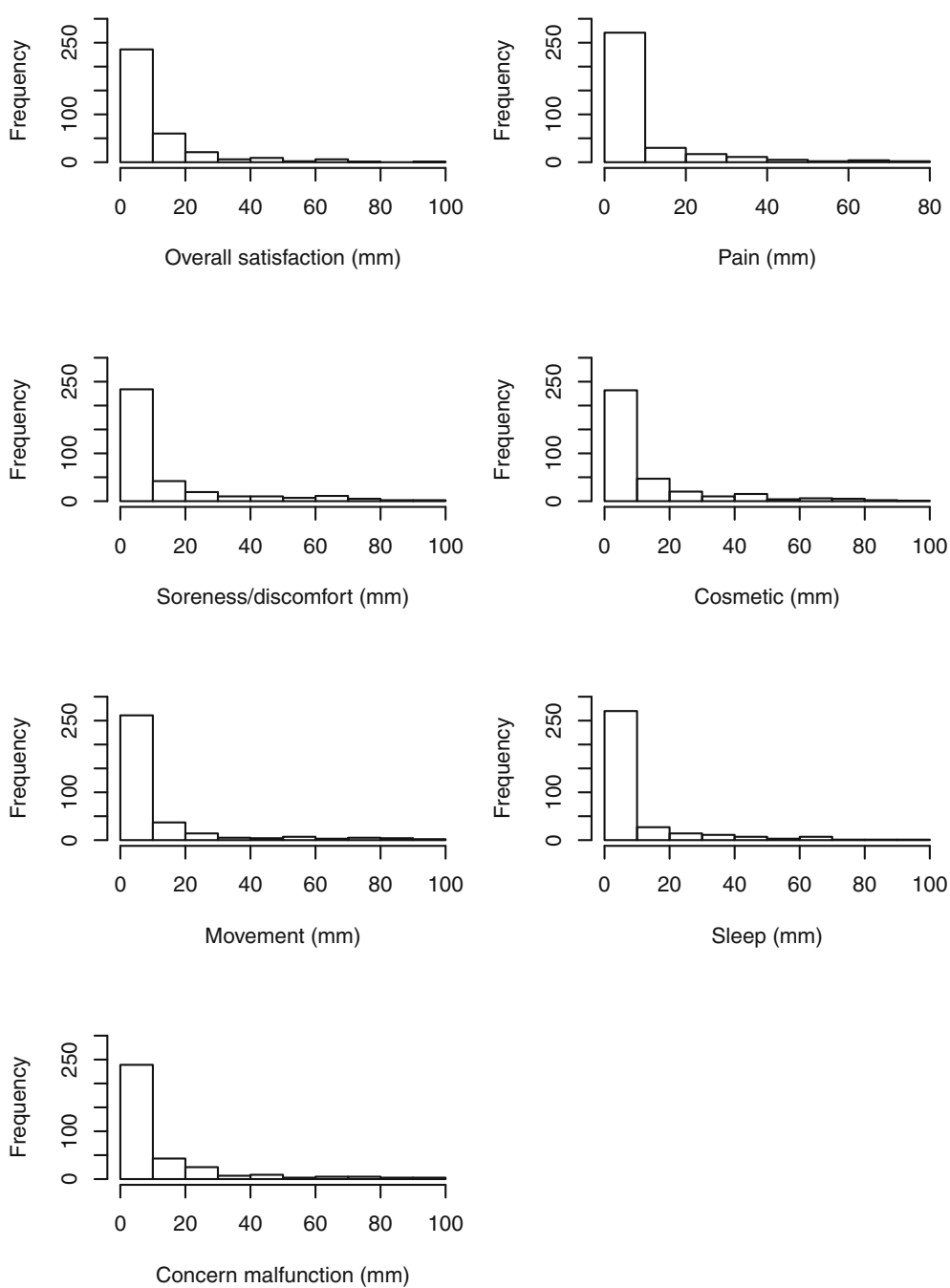

Fig. 2 Histogram of frequency and outcome of pacemaker-patient reporting on a $100 \mathrm{~mm}$ scale. A higher score indicates worse outcome 
Table 2 Percentile distribution and mean values (standard deviations) of responses on VAS-scale $(\mathrm{mm})$

\begin{tabular}{lllllll}
\hline Question & $5 \%$ & $25 \%$ & $50 \%$ & $75 \%$ & $95 \%$ & Mean(SD) \\
\hline Overall satisfaction & 0 & 2 & 5 & 13 & 44.9 & $10.3(14.1)$ \\
Pain & 0 & 1 & 3 & 8 & 38 & $8.3(13.1)$ \\
Soreness/discomfort & 0 & 2 & 4 & 14 & 62 & $13(19.5)$ \\
Cosmetic results & 0 & 2 & 5 & 15.8 & 50.9 & $12.4(17.9)$ \\
Movement & 0 & 1 & 4 & 10 & 53.9 & $10.3(17.8)$ \\
Sleep & 0 & 2 & 4 & 9 & 44.8 & $9.2(14.8)$ \\
Concern about malfunction & 0 & 2 & 4 & 13 & 52.9 & $11.7(18.4)$ \\
\hline
\end{tabular}

rho $=-0.21, \mathrm{p}<0.001 ;$ Soreness $/$ discomfort rho $=-0.16$, $p=0.01$; cosmetic rho $=-0.16, \mathrm{p}=0.01$; movement rho $=-0.22, \mathrm{p}=0.01$; sleep rho $=-0.19, \mathrm{p}=0.01$; concern malfunction rho $=-0.09, p=0.04$ ).

\section{Discussion}

Pacemaker implantation typically results in lifelong therapy. From a healthcare perspective, complications related to pacemaker implantation may require surgical interventions as well as extra follow-up visits, either in-clinic or remotely by using home-monitoring. Notably, 10 patients complained about the device position and underwent surgical intervention to reposition the pacemaker. Clinicians may hesitate before making the decision to surgically correct the pacemaker pocket, because it increases the risk of infection and lead damage, which may necessitate lead extractions that involve serious risks and expense [13-16].

\section{Most patients report overall satisfaction}

In the present study, the vast majority claimed very high overall satisfaction and further analyses of secondary outcomes confirmed this. Nevertheless, a non-neglible proportion of the patients reported complaints which did not result in surgical revisions because they were not addressed clinically. It is not clear from our study why some patient complaints were not identified during their follow-up.
Females more often report pain, soreness/discomfort, and sleep disturbances

We found statistically significant differences in reported overall satisfaction, pain soreness/discomfort and sleep between the sexes, where females more frequently reported worse outcome than males. Since females are generally smaller,the device may more readily impede arm movement. Interestingly, there were few patients who reported cosmetic problems and there was no difference between males and females in the assessment of cosmetic results. Although the study population was $57 \%$ men, among the patients who underwent surgical revision to correct pacemaker position in the pocket, $50 \%$ were women $(n=5)$.

\section{Age, BMI, reoperation}

Interestingly, neither age nor BMI seemed to affect the patient-reported outcomes for our survey. The fact that re-operation was not associated with worse outcome is reassuring, but it still must be remembered that surgical revision increases the risk of infection and may require lead extraction. From the perspective of each individual patient, it is important to take every measure to avoid reoperation due to complications and consider the optimal technique for pacemaker and lead placement at the initial implantation $[17,18]$.

\section{Future perspectives}

This study provides insights into the perceptions of pacemaker patients about their device therapy. Despite the increasing proportion of home-monitoring devices, which have improved patient safety and clinical logistics, it is still important to evaluate outcomes from a holistic and pacemaker-patient-centric viewpoint. The creation of the pocket during the initial implantation is crucial. There is an ongoing trial designed to address whether intramuscular implantation is superior to a subcutaneous pocket for initial pacemaker placement [19].

The introduction of a new leadless pacemaker (Micra ${ }^{\mathrm{TM}}$ ) may eliminate problems due to the pocket and leads. However, this device has limited availability, few indications, and may be cost prohibitive [20, 21]. Rechargeable

Table 3 Median and interquartile range (IQR) with regard to sex and reoperation ( $p$-value using Mann-Whitney U-test)

\begin{tabular}{|c|c|c|c|c|c|c|}
\hline Question & Females, median (IQR) & Males, median (IQR) & $p$-value & No reop, median (IQR) & Reoperation, median (IQR) & $p$-value \\
\hline Overall satisfaction & $6(3-15.5)$ & $5(2-11.5)$ & 0.042 & $6(2-14)$ & $4(2-11)$ & 0.142 \\
\hline Pain & $4(2-11)$ & $3(1-7)$ & 0.025 & $3(2-9)$ & $3(1-8)$ & 0.612 \\
\hline Soreness/discomfort & $6(2-20)$ & $4(1-11)$ & 0.002 & $4(2-14)$ & $5(2-15)$ & 0.568 \\
\hline Cosmetic results & $5(2-17)$ & $4(2-14)$ & 0.201 & $4(2-13)$ & $7(2-21)$ & 0.043 \\
\hline Movement & $4(2-13)$ & $3(1-8)$ & 0.079 & $4(1-10)$ & $3(1-8)$ & 0.958 \\
\hline Sleep & $5(2-11.5)$ & $3(1-7)$ & 0.009 & $4(2-8)$ & $3(1-9)$ & 0.595 \\
\hline Concern about malfunction & $5(2-13.5)$ & $4(1-12)$ & 0.12 & $5(2-13)$ & $3(2-11)$ & 0.253 \\
\hline
\end{tabular}


pacemakers seem to offer the theoretical advantages of reducing device replacements, but there are no rechargeable devices currently on the market.

\section{Strengths and weaknesses}

This study evaluates pacemaker therapy from the patient perspective, going beyond data in registries in order to address patient attitudes without the potential bias that could be introduced by interviewing patients during clinical follow-up. Many of our respondents were elderly and some suffered cognitive impairments and were not able to follow instructions, even though the questionnaire was short and straightforward. Nonresponders tended to be older than respondents, but males and females participated in the study to the same extent.In order to overcome the limitations of a cross-sectional study design, repeated outcome assessments at predefined follow-up periods are required. Psychological coping strategies, like adaptation, were not addressed. Finally, we would like to point out that multiple statistical tests were performed in our study, but no correction for mass significance has been made, which means that caution is warranted when interpreting individual tests. An alternative approach would have to perform such corrections to reduce the risk of statistical type 1-errors, but at the cost of an increased risk of type 2-errors.

\section{Conclusion}

The vast majority of pacemaker patients report excellent overall satisfaction with their pacemaker system, including the absence of pain, no soreness/discomfort, acceptable cosmetic results, good shoulder movement, sound sleep, and no concerns about device malfunction. In $2.9 \%$ of the study population, a surgical procedure was need to correct device placement. Females report worse overall satisfaction, pain, soreness/discomfort, and more sleep problems related to the pacemaker.

\section{Abbreviations}

BMI: body mass index; CRT: cardiac resynchronization therapy;

IQR: interquartile range; SD: standard deviation; VAS: visual analog scale

\section{Acknowledgements}

The authors acknowledge editing by Jo Ann LeQuang of LeQ Medical who reviewed the manuscript for American English use. Thanks to Julia Fahlstedt and Therese Martinell for administrative support.

\section{Funding}

Region Gävleborg funded this research project.

\section{Availability of data and materials}

The datasets used and analysed during the current study are available from the corresponding author on reasonable request.

\section{Authors' contributions}

PM: project idea, design, data collection and analysis, major writing of the manuscript, project management. PL: design with regard to statistical issues, data collection and analysis, critical revision of the manuscript. Both authors approved the manuscript for submission.
Ethics approval and consent to participate

The study was approved by the Regional Ethical committee in Uppsala (Dnr 2015/060). All patients gave their written consent to participate in the study.

Competing interests

The authors declare that they have no competing interests.

\section{Publisher's Note}

Springer Nature remains neutral with regard to jurisdictional claims in published maps and institutional affiliations.

Received: 21 June 2017 Accepted: 24 May 2018

Published online: 04 June 2018

References

1. Brignole $M$, Auricchio A, Baron-Esquivias G, Bordachar P, Boriani G, Breithardt OA, Cleland J, et al. 2013 ESC guidelines on cardiac pacing and cardiac resynchronization therapy: the task force on cardiac pacing and resynchronization therapy of the European Society of Cardiology (ESC). Developed in collaboration with the European heart rhythm association (EHRA). Europace. 2013:15:1070-118.

2. www.eucomed.org/medical-technology/facts-figures

3. Ellenbogen KA, Hellkamp AS, Wilkoff BL, Camunas JL, Love JC, Hadjis TA Lee $\mathrm{KL}$, et al. Complications arising after implantation of DDD pacemakers: the MOST experience. Am J Cardiol. 2003:92:740-1.

4. Udo EO, Zuithoff NP, van Hemel NM, de Cock CC, Hendriks T, Doevendans PA, Moons KG. Incidence and predictors of short- and long-term complications in pacemaker therapy: the FOLLOWPACE study. Heart Rhythm. 2012;9:728-35.

5. Eberhardt F, Bode F, Bonnemeier H, Boguschewski F, Schlei M, Peters W, Wiegand UK. Long term complications in single and dual chamber pacing are influenced by surgical experience and patient morbidity. Heart. 2005;91: 500-6.

6. Gadler F, Valzania C, Linde C. Current use of implantable electrical devices in Sweden: data from the Swedish pacemaker and implantable cardioverterdefibrillator registry. Europace. 2015:17:69-77.

7. https://ssl.icddata.dk/download/Danish_Pacemaker_and_ICD_Register_ Annual_Report_2015b.pdf

8. Kirkfeldt RE, Johansen JB, Nohr EA, Jorgensen OD, Nielsen JC. Complications after cardiac implantable electronic device implantations: an analysis of a complete, nationwide cohort in Denmark. Eur Heart J. 2014;35:1186-94.

9. Udo EO, van Hemel NM, Zuithoff NP, Nijboer H, Taks W, Doevendans PA, Moons KG. Long term quality-of-life in patients with bradycardia pacemaker implantation. Int J Cardiol. 2013;168:2159-63.

10. Stofmeel MA, Post MW, Kelder JC, Grobbee DE, van Hemel NM. Quality-oflife of pacemaker patients: a reappraisal of current instruments. Pacing Clin Electrophysiol. 2000;23:946-52.

11. World Health Organization . International Classification of Diseases (ICD)". Retrieved 2017.

12. Statistics Sweden Database. Official population statistics. 2015. www.scb.se/ BE0101

13. Buch E, Boyle NG, Belott PH. Pacemaker and defibrillator lead extraction. Circulation. 2011;123:378-80

14. Johansen JB, Jorgensen OD, Moller M, Arnsbo P, Mortensen PT, Nielsen JC, et al. Infection after pacemaker implantation: infection rates and risk factors associated with infection in a population-based cohort study of 46299 consecutive patients. Eur Heart J. 2011;32:991-8.

15. Kirkfeldt RE, Johansen JB, Nohr EA, Moller M, Arnsbo P, Nielsen JC, et al. Risk factors for lead complications in cardiac pacing: a population-based cohort study of 28,860 Danish patients. Heart Rhythm. 2011:8:1622-8.

16. Tobin K, Stewart J, Westveer D, Frumin H. Acute complications of permanent pacemaker implantation: their financial implication and relation to volume and operator experience. Am J Cardiol. 2000;85:774-6.

17. Rajappan K. Permanent pacemaker implantation technique: part I: arrhythmias. Heart. 2009:95:259-64.

18. Rajappan K. Permanent pacemaker implantation technique: part II. Heart. 2009:95:334-42

19. Magnusson P, Wennström L, Kastberg R, Liv P. Placement of cardiac PacemaKEr trial (POCKET) - rationale and design: a randomized controlled trial. Heart Int. 2017;12(1):e8-e11. 
20. Reynolds DW, Duray GZ, Omar R, Soejima K, Neuzil P, Zhang S, Narasimhan C, et al. A leadless Intracardiac Transcatheter pacing system. N Engl J Med. 2016;374(6):533-41.

21. Duray GZ, Ritter P, El-Chami M, Narasimhan C, Omar R, Tolosana JM, Zhang

$\mathrm{S}$, et al. Micra Transcatheter pacing study group. Long-term performance of a transcatheter pacing system: 12-month results from the Micra

Transcatheter pacing study. Heart Rhythm. 2017;14(5):702-9.

- fast, convenient online submission

- thorough peer review by experienced researchers in your field

- rapid publication on acceptance

- support for research data, including large and complex data types

- gold Open Access which fosters wider collaboration and increased citations

- maximum visibility for your research: over $100 \mathrm{M}$ website views per year 